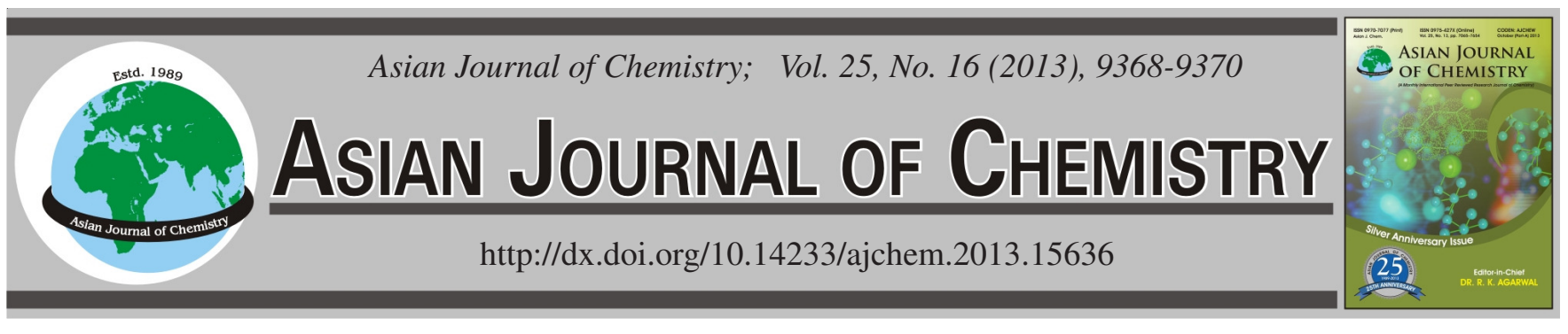

\title{
Synthesis and Characterization of 5,5',6,6'-Tetrahydroxy-2,2'-[ethylene-1,2- diyldioxy)bis(nitrilomethylidyne)]diphenol and its Copper(II) Complexes
}

\author{
Feng-Ying Chai ${ }^{1}$, Zheng-Kun Wang ${ }^{2}$, Meng-Meng ZhaO ${ }^{2}$, Xin-Ying Zhang ${ }^{2}$, \\ JiaO-Long Meng ${ }^{2}$, LI-Sha Zhang ${ }^{2}$ and Ke-TaI WAnG ${ }^{1, *}$
}

\begin{abstract}
${ }^{1}$ School of Chemical Engineering, Lanzhou University of Arts and Sciences, Lanzhou 730000, P.R. China
${ }^{2}$ School of Chemical and Biological Engineering, Lanzhou Jiaotong University, Lanzhou 730070, P.R. China

*Corresponding author: E-mail: wang_kt@126.com
\end{abstract}

\section{INTRODUCTION}

Salen (N,N'-bis(salicylaldehydo)ethylenediamine) and its derivatives are well-known chelating ligands in modern coordination chemistry ${ }^{1-3}$. During the past few decades, metallo-salen complexes have been of considerable current interest due to their interesting properties ${ }^{4}$, such as excellent catalytic activity for epoxidation and aziridination ${ }^{5}$. In addition, they are also used as models for reaction centers in metalloenzymes ${ }^{6}$, nonlinear optical materials ${ }^{7}$ and molecular recognition and biological activity ${ }^{8}$. Herein, a new Salen-type bisoxime chelating ligand $\left(\mathrm{H}_{6} \mathrm{~L}=5,5^{\prime}, 6,6^{\prime}\right.$-tetrahydroxy-2,2'-[ethylene-1,2diyldioxy)bis(nitrilomethylidyne)]diphenol) and its $\mathrm{Cu}(\mathrm{II})$ complexes have been synthesized and structurally characterized.

\section{EXPERIMENTAL}

2,3,4-Trihydroxy benzaldehyde $(\geq 98.5 \%)$ was purchased from Sinopharm Chemical Reagent Co., Ltd. and used without further purification. 1,2-Bis(aminooxy)ethane was synthesized according to an analogous method reported earlier ${ }^{6}$. Copper(II) acetate monohydrate ( $\geq 98.5 \%$ ), copper(II) chloride dihydrate ( $\geq 99 \%$ ), copper(II) nitrate tetrahydrate ( $\geq 99 \%$ ), the other reagents and solvents were purchased from Tianjin Chemical Reagent Factory and were used without further purification. Copper was detected by an IRIS ER/S.WP-1 ICP atomic emission spectrometer. $\mathrm{C}, \mathrm{H}$ and $\mathrm{N}$ analyses were carried out with a GmbH VariuoEL V3.00 automatic elemental analyzer. FT-IR spectra were recorded on a VERTEX70 FT-IR spectrophotometer, with samples prepared as $\mathrm{KBr}\left(4000-400 \mathrm{~cm}^{-1}\right)$. UVVIS absorption spectra were recorded on a Shimadzu UV-2550 spectrometer. Molar conductance value measurements were carried out on a model DDS-11D type conductivity bridge using $1.0 \times 10^{-3} \mathrm{~mol} \cdot \mathrm{dm}^{-3}$ solution in DMF at $25^{\circ} \mathrm{C}$.

Synthesis of ligand $\mathbf{H}_{6} \mathbf{L}$ : The ligand $\mathrm{H}_{6} \mathrm{~L}$ was synthesized with a slightly modified method reported literature ${ }^{4}$. Synthetic route to salen-type bisoxime ligand $\mathrm{H}_{6} \mathrm{~L}$ is shown in Fig. 1.
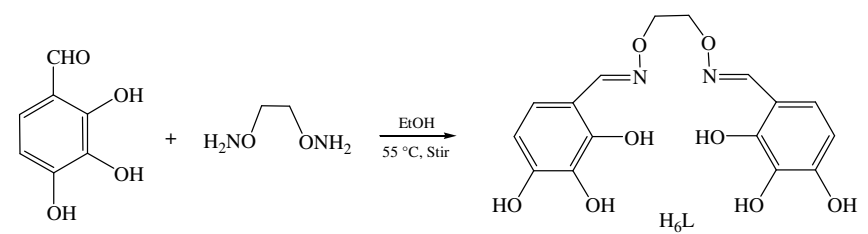

Fig. 1. Synthetic route to 5,5',6,6'-tetrahydroxy-2,2'-[ethylene-1,2-diyldioxy) bis(nitrilomethylidyne)]diphenol $\left(\mathrm{H}_{6} \mathrm{~L}\right)$

Reaction of 1,2-bis(aminooxy)ethane (133.5 mg, 1.45 mmol) with 2 equivalents of 2,3,4-trihydroxy benzaldehyde (462.4 mg, $3 \mathrm{mmol})$ in ethanol $(10 \mathrm{~mL})$ at $55^{\circ} \mathrm{C}$ for $6 \mathrm{~h}$. After cooled to room temperature, the resulting solid was filtered and washed with ethanol and ethanol/hexane (1:4), respectively. The product was dried in vacuo and obtained $483.7 \mathrm{mg}$ of white microcrystal. Yield: $79.8 \%$.

Synthesis of complex 1: A solution of copper(II) acetate monohydrate $(20 \mathrm{mg}, 0.10 \mathrm{mmol})$ in ethanol $(3 \mathrm{~mL})$ was added 
dropwise to a solution of $\mathrm{H}_{6} \mathrm{~L}(36.6 \mathrm{mg}, 0.10 \mathrm{mmol})$ in ethanol $(3 \mathrm{~mL})$ at room temperature. A green solution was obtained and stirred vigorously and refluxed for $12 \mathrm{~h}$. The resulting reaction solution was concentrated under reduced pressure. After cooled to room temperature, the precipitation formed was filtered and washed with ethanol/ether (1:4) and ether, respectively. The product was dried in vacuo and obtained 19 mg of black solid (Yield 29.0\%).

Synthesis of complex 2: To an ethanolic solution $(5 \mathrm{~mL})$ of $\mathrm{H}_{6} \mathrm{~L}$ ( $36.5 \mathrm{mg}, 0.10 \mathrm{mmol}$ ) was added an ethanolic solution (5 mL) of copper(II) picrate tetrahydrate $(59.2 \mathrm{mg}, 0.10 \mathrm{mmol})$. After the mixture solution had been stirred at $55^{\circ} \mathrm{C}$ for $10 \mathrm{~h}$, the formed precipitate was separated by filtration and washed successively with ethanol/ether (1:4) and ether, respectively. The product was dried under reduced pressure to obtain 32.4 mg of yellow solid (Yield 39.3\%).

Synthesis of complex 3: A solution of copper(II) nitrate trihydrate $(24.2 \mathrm{mg}, 0.10 \mathrm{mmol})$ in ethanol $(6 \mathrm{~mL})$ was added dropwise to a solution of $\mathrm{H}_{6} \mathrm{~L}(36.3 \mathrm{mg}, 0.10 \mathrm{mmol})$ in ethanol $(3 \mathrm{~mL})$ at room temperature. A green solution was obtained and stirred vigorously and refluxed for $8 \mathrm{~h}$. The resulting reaction solution was concentrated under reduced pressure. After cooled to room temperature, the precipitate formed was filtered and washed with ethanol/ether (1:4) and ether, respectively. The product was dried in vacuo and obtained $25.6 \mathrm{mg}$ of black solid (Yield $48.9 \%$ ).

Synthesis of complex 4: To an ethanolic solution ( $5 \mathrm{~mL})$ of $\mathrm{H}_{6} \mathrm{~L}$ (36.4 mg, $0.10 \mathrm{mmol}$ ) was added an ethanolic solution (6 mL) of copper(II) chloride dihydrate $(17.1 \mathrm{mg}, 0.10 \mathrm{mmol})$. A green solution was obtained and stirred vigorously and refluxed for $10 \mathrm{~h}$. The formed precipitate was separated by filtration and washed successively with ethanol/ether (1:4) and ether, respectively. The product was dried under reduced pressure to obtain $11.8 \mathrm{mg}$ of black solid (Yield $21.4 \%$ ).

\section{RESULTS AND DISCUSSION}

A Salen-type bisoxime compound $\mathrm{H}_{6} \mathrm{~L}$ and its $\mathrm{Cu}$ (II) complexes have been synthesized with good yields and the compositions are confirmed by elemental analyses, IR, UVvisible spectra and molar conductances.
Composition of $\mathrm{Cu}(\mathrm{II})$ complexes: The colour, yields and analytical results of the $\mathrm{Cu}(\mathrm{II})$ complexes are given in Table-1.

Their compositions agree with the formula $\left[\mathrm{Cu}_{3}(\mathrm{HL})\right.$ $\left.\left(\mathrm{CH}_{3} \mathrm{COO}\right)\right] \cdot \mathrm{EtOH}$ for complex 1, $\left[\mathrm{Cu}_{3}(\mathrm{HL})(\mathrm{pic})\right] \cdot \mathrm{EtOH}$ for complex 2, $\left[\mathrm{Cu}_{3}(\mathrm{HL})\left(\mathrm{NO}_{3}\right)\right] \cdot \mathrm{H}_{2} \mathrm{O}$ for complex 3 and $\left[\mathrm{Cu}_{3}(\mathrm{HL}) \mathrm{Cl}\right] \cdot 2 \mathrm{H}_{2} \mathrm{O}$ for complex 4 . The molar conductance values of the $\mathrm{Cu}$ (II) complexes in $1.0 \times 10^{-3} \mathrm{~mol} \mathrm{dm}^{-3} \mathrm{DMF}$ solutions at $21{ }^{\circ} \mathrm{C}$ are shown in Table-1. Compared with the molar conductance values about different types of electrolytes in organic solvents, we can consider that the formed $\mathrm{Cu}$ (II) complexes are non-electrolytes, indicating the anions in the $\mathrm{Cu}$ (II) complexes are coordinated to the $\mathrm{Cu}$ (II) ions ${ }^{9}$.

IR spectra of $\mathbf{H}_{6} \mathrm{~L}$ and $\mathrm{Cu}(\mathrm{II})$ complexes: The most important FT-IR spectra data for $\mathrm{H}_{6} \mathrm{~L}$ and its $\mathrm{Cu}$ (II) complexes are given in Table-2. From the results of IR spectra, the ligand and its $\mathrm{Cu}(\mathrm{II})$ complexes are very different, which proves that $\mathrm{Cu}$ (II) ions have been in coordination with the (HL) ${ }^{5-}$ unit and new complexes formed. The characteristic $\mathrm{C}=\mathrm{N}$ stretching band of the free ligand $\mathrm{H}_{6} \mathrm{~L}$ appears at $1615.7 \mathrm{~cm}^{-1}$, while the $\mathrm{C}=\mathrm{N}$ stretching bands of the $\mathrm{Cu}(\mathrm{II})$ complexes are observed at 1591.0-1606.2 $\mathrm{cm}^{-1}$. The $\mathrm{C}=\mathrm{N}$ stretching frequency shifted to lower frequency by $24.7-9.5 \mathrm{~cm}^{-1}$ upon complexation, indicating a decrease in the $\mathrm{C}=\mathrm{N}$ bond order due to the coordinated bonds of the $\mathrm{Cu}(\mathrm{II})$ atoms with the oxime nitrogen lone pair ${ }^{10}$. The Ar-O stretching frequency appears as a strong band within $1263-1213 \mathrm{~cm}^{-1}$ range as reported for similar ligands ${ }^{11-13}$. This band occurs at $1219 \mathrm{~cm}^{-1}$ for $\mathrm{H}_{6} \mathrm{~L}$ and at $1264.5-1240.2 \mathrm{~cm}^{-1}$ for the $\mathrm{Cu}$ (II) complexes. The Ar-O stretching frequency is shifted to lower frequency, indicating that the $\mathrm{Cu}-\mathrm{O}$ bond was formed between the $\mathrm{Cu}$ (II) ion and oxygen atom of phenolic group $^{10,14}$. In addition, the $\mathrm{O}-\mathrm{H}$ stretching band of the free ligand $\mathrm{H}_{6} \mathrm{~L}$ appears at $3453.1 \mathrm{~cm}^{-1}$ and a very broad absorption band at $3431.3-3406.5 \mathrm{~cm}^{-1}$ in the $\mathrm{Cu}$ (II) complex is assigned to phenolic alcohol group of the $(\mathrm{HL})^{5-}$ unit and $-\mathrm{OH}$ groups of non-coordinated ethanol or water molecules.

UV-visible spectra of $\mathbf{H}_{6} \mathbf{L}$ and $\mathbf{C u}(\mathrm{II})$ complexes: The UV-visible absorption spectra of $\mathrm{H}_{6} \mathrm{~L}$ and its $\mathrm{Cu}$ (II) complexes in diluted DMF solution are presented in Table-3. The absorption spectra of the $\mathrm{Cu}$ (II) complexes are similar to each

\begin{tabular}{|c|c|c|c|c|c|c|c|}
\hline \multicolumn{8}{|c|}{$\begin{array}{l}\text { TABLE- } 1 \\
\text { COLOUR, YIELDS AND ANALYTICAL DATA OF } \mathrm{H}_{6} \mathrm{~L} \text { AND ITS Cu(II) COMPLEXES }\end{array}$} \\
\hline \multirow[b]{2}{*}{ Compound } & \multirow[b]{2}{*}{ m.f. (m.w.) } & \multirow[b]{2}{*}{ Colour } & \multirow{2}{*}{$\begin{array}{l}\text { Yield } \\
(\%)\end{array}$} & \multicolumn{3}{|c|}{$\begin{array}{l}\text { Found (calcd.) }(\%) \\
\end{array}$} & \multirow{2}{*}{$\begin{array}{c}\text { Molar } \\
\text { conductance } \\
\left(\mathrm{S} \mathrm{cm}^{2} \mathrm{~mol}^{-1}\right)\end{array}$} \\
\hline & & & & $\mathrm{C}$ & $\mathrm{H}$ & $\mathrm{N}$ & \\
\hline $\mathrm{H}_{6} \mathrm{~L}$ & $\mathrm{C}_{16} \mathrm{H}_{16} \mathrm{~N}_{2} \mathrm{O}_{8}(364.3)$ & White & 79.8 & $53.0052 .75)$ & $4.39(4.43)$ & $7.37(7.69)$ & - \\
\hline$\left[\mathrm{Cu}_{3}(\mathrm{HL})\left(\mathrm{CH}_{3} \mathrm{COO}\right)\right] \cdot \mathrm{EtOH}$ & $\mathrm{C}_{20} \mathrm{H}_{20} \mathrm{Cu}_{3} \mathrm{~N}_{2} \mathrm{O}_{11}(655.0)$ & Black & 29.0 & $36.60(36.62)$ & $2.84(3.23)$ & $4.16(4.27)$ & 6.62 \\
\hline$\left[\mathrm{Cu}_{3}(\mathrm{HL})(\mathrm{pic})\right] \cdot \mathrm{EtOH}$ & $\mathrm{C}_{24} \mathrm{H}_{19} \mathrm{Cu}_{3} \mathrm{~N}_{5} \mathrm{O}_{16}(824.1)$ & Yellow & 39.3 & $34.88(34.98)$ & $2.28(2.32)$ & $8.60(8.50)$ & 8.87 \\
\hline$\left[\mathrm{Cu}_{3}(\mathrm{HL})\left(\mathrm{NO}_{3}\right)\right] \cdot \mathrm{H}_{2} \mathrm{O}$ & $\mathrm{C}_{16} \mathrm{H}_{13} \mathrm{Cu}_{3} \mathrm{~N}_{3} \mathrm{O}_{12}(627.8)$ & Black & 48.9 & $30.54(30.51)$ & $2.29(2.08)$ & $6.68(6.67)$ & 1.15 \\
\hline$\left[\mathrm{Cu}_{3}(\mathrm{HL}) \mathrm{Cl}\right] \cdot 2 \mathrm{H}_{2} \mathrm{O}$ & $\mathrm{C}_{16} \mathrm{H}_{15} \mathrm{ClCu}_{3} \mathrm{~N}_{2} \mathrm{O}_{10}(618.8)$ & Black & 21.4 & $30.49(30.93)$ & $2.55(2.43)$ & $4.87(4.51)$ & 2.34 \\
\hline \multicolumn{8}{|c|}{$\begin{array}{c}\text { TABLE-2 } \\
\text { IR SPECTRAL }\left(\mathrm{cm}^{-1}\right) \text { DATA FOR } \mathrm{H}_{6} L \text { AND ITS Cu(II) COMPLEXES }\end{array}$} \\
\hline Compound & $v(\mathrm{C}=\mathrm{N})$ & \multicolumn{2}{|c|}{$v(\mathrm{Ar}-\mathrm{O})$} & \multicolumn{2}{|c|}{$v(\mathrm{O}-\mathrm{H})$} & \multicolumn{2}{|c|}{$v(\mathrm{C}=\mathrm{C})$ benzene ring skeleton } \\
\hline $\mathrm{H}_{6} \mathrm{~L}$ & 1615.7 & \multicolumn{2}{|c|}{1292.0} & \multicolumn{2}{|c|}{3453.1} & \multicolumn{2}{|c|}{$1595.2,1525.0,1471.1$} \\
\hline$\left[\mathrm{Cu}_{3}(\mathrm{HL})\left(\mathrm{CH}_{3} \mathrm{COO}\right)\right] \cdot \mathrm{EtOH}$ & 1594.6 & \multicolumn{2}{|c|}{1250.7} & \multicolumn{2}{|c|}{3406.5} & \multicolumn{2}{|c|}{$1585.3,1489.6,1450.5$} \\
\hline$\left[\mathrm{Cu}_{3}(\mathrm{HL})(\mathrm{pic})\right] \cdot \mathrm{EtOH}$ & 1606.2 & \multicolumn{2}{|c|}{1264.5} & \multicolumn{2}{|c|}{3430.1} & \multicolumn{2}{|c|}{$1586.2,1490.4,1451.9$} \\
\hline$\left[\mathrm{Cu}_{3}(\mathrm{HL})\left(\mathrm{NO}_{3}\right)\right] \cdot \mathrm{H}_{2} \mathrm{O}$ & 1599.8 & \multicolumn{2}{|c|}{1256.4} & \multicolumn{2}{|c|}{3431.3} & \multicolumn{2}{|c|}{$1587.0,1493.8,1440.2$} \\
\hline$\left[\mathrm{Cu}_{3}(\mathrm{HL}) \mathrm{Cl}\right] \cdot 2 \mathrm{H}_{2} \mathrm{O}$ & 1591.0 & \multicolumn{2}{|c|}{1240.2} & \multicolumn{2}{|c|}{3410.2} & \multicolumn{2}{|c|}{$1572.6,1478.1,1446.4$} \\
\hline
\end{tabular}


TABLE-3

UV-VISIBLE SPECTRAL DATA OF $\mathrm{H}_{6}$ L AND ITS Cu(II) COMPLEXES

\begin{tabular}{lccccc}
\hline \multirow{2}{*}{ Compound } & \multirow{2}{*}{$\mathrm{C}\left(\times 10^{-4} \mathrm{~mol} \mathrm{~L}^{-1}\right)$} & \multicolumn{3}{c}{ First band } & \multicolumn{2}{c}{ Second band } \\
\cline { 3 - 6 } & & $\lambda_{\max 1}(\mathrm{~nm})$ & $\varepsilon_{1}\left(\times 10^{4} \mathrm{~L} \mathrm{~mol}^{-1} \mathrm{~cm}^{-1}\right)$ & $\lambda_{\max 2}(\mathrm{~nm})$ & $\varepsilon_{2}\left(\times 10^{4} \mathrm{~L} \mathrm{~mol}^{-1} \mathrm{~cm}^{-1}\right)$ \\
\hline $\mathrm{H}_{6} \mathrm{~L}$ & 1.00 & 283 & 13.01 & 386 & 4.18 \\
{$\left[\mathrm{Cu}_{3}(\mathrm{HL})\left(\mathrm{CH}_{3} \mathrm{COO}\right)\right] \cdot \mathrm{EtOH}$} & 1.00 & 268 & 1.70 & 332 & 1.60 \\
{$\left[\mathrm{Cu}_{3}(\mathrm{HL})(\mathrm{pic})\right] \cdot \mathrm{EtOH}$} & 1.00 & 261 & 2.08 & 330 & 1.78 \\
{$\left[\mathrm{Cu}_{3}(\mathrm{HL})\left(\mathrm{NO}_{3}\right)\right] \cdot \mathrm{H}_{2} \mathrm{O}$} & 1.00 & 258 & 1.68 & 334 & 1.55 \\
{$\left[\mathrm{Cu}_{3}(\mathrm{HL}) \mathrm{Cl}\right] \cdot 2 \mathrm{H}_{2} \mathrm{O}$} & 1.00 & 263 & 1.85 & 338 & 1.68 \\
\hline
\end{tabular}

other, but are different from the spectrum of the free ligand $\mathrm{H}_{6} \mathrm{~L}$. The UV-visible spectrum of the free ligand $\mathrm{H}_{6} \mathrm{~L}$ exhibits one absorption peak at $283 \mathrm{~nm}$, which can be assigned to the $\pi-\pi^{*}$ transition of the benzene rings ${ }^{15}$. Compared with the absorption peak of the free ligand $\mathrm{H}_{6} \mathrm{~L}$, a corresponding absorption peak at $258-268 \mathrm{~nm}$ is observed in the $\mathrm{Cu}(\mathrm{II})$ complexes, which is shifted by $15-25 \mathrm{~nm}$, indicating the coordination of the $\mathrm{Cu}$ (II) ions with the (HL) ${ }^{5-}$ unit. Meanwhile, a new absorption peak is observed at $330-338 \mathrm{~nm}$ in the $\mathrm{Cu}(\mathrm{II})$ complexes, which is assigned to the $n-\pi^{*}$ charge transfer transition from the filled $p \pi$ orbital of the bridging phenolic oxygen to the vacant $d$-orbital of the $\mathrm{Cu}(\mathrm{II})$ ions ${ }^{16,17}$.

\section{REFERENCES}

1. D. Hall and T.N. Waters, J. Chem. Soc., 2644 (1960).

2. J. Reglinski, S. Morris and D.E. Stevenson, Polyhedron, 21, 2167 (2002).

3. A.D. Garnovski, A.L. Nivorozhkin and V.I. Minki, Coord. Chem. Rev., 126, 1 (1993).

4. (a) W.K. Dong, Y.X. Sun, Y.P. Zhang, L. Li, X.N. He and X.L. Tang, Inorg. Chim. Acta, 362, 117 (2009); (b) W.K. Dong, Y.X. Sun, C.Y. Zhao, X.Y. Dong and L. Xu, Polyhedron, 29, 2087 (2010); (c) W.K. Dong, X.N. He, H.B. Yan, Z.W. Lv, X. Chen, C.Y. Zhao and X.L. Tang,
Polyhedron, 28, 1419 (2009); (d) W.K. Dong, J.G. Duan, Y.H. Guan, J.Y. Shi and C.Y. Zhao, Inorg. Chim. Acta, 362, 1129 (2009); (e) W.K. Dong, L. Li, C.F. Li, L. Xu and J.G. Duan, Spectrochim. Acta A, 71, 650 (2008).

5. N.S. Venkataramanan, G. Kuppuraj and S. Rajagopal, Coord. Chem. Rev., 249, 1249 (2005).

6. M.F. Summers, L.G. Marzilli, N. Bresciani-Pahor and L. Randaccio, J. Am. Chem. Soc., 106, 4478 (1984).

7. P.G. Lacroix, Eur. J. Inorg. Chem., 339 (2001).

8. S.S. Sun, C.L. Stern, S.T. Nguyen and J.T. Hupp, J. Am. Chem. Soc., 126, 6314 (2004)

9. W.J. Geary, Coord. Chem. Rev., 1, 81 (1971).

10. G.A. Kohawole and K.S. Patel, J. Chem. Soc. Dalton Trans., 1241 (1981).

11. K. Ueno and A.E. Martel, J. Phys. Chem., 60, 1270 (1956).

12. J.A. Faniran, K.S. Patel and J.C. Bailar, J. Inorg. Nucl. Chem., 36, 1547 (1974).

13. G.C. Percy and J. Thornton, J. Inorg. Nucl. Chem., 35, 2319 (1973).

14. M. Asadi, K.A. Jamshid and A.H. Kyanfar, Inorg. Chim. Acta, 360, 1725 (2007).

15. T. Ghosh, B. Mondal, T. Ghosh, M. Sutradhar, G. Mukherjee and M.G.B. Drew, Inorg. Chim. Acta, 360, 1753 (2007).

16. H.E. Smith, Chem. Rev., 83, 359 (1983).

17. S. Akine, T. Taniguchi and T. Nabeshima, Chem. Lett., 30, 682 (2001). 